\title{
The influence of genetic polymorphisms in TLR4 and TIRAP, and their expression levels in peripheral blood, on susceptibility to sepsis
}

\author{
JIANPING ZHANG ${ }^{1}$, JINGPING YANG $^{2}$, XIYUAN XU $^{2}$, LIANGSHEN LIANG ${ }^{1}$, \\ HAIXIA SUN ${ }^{1}$, GUOHUA LIU ${ }^{1}$, LIHONG ZHANG ${ }^{1}$ and YUN SU ${ }^{1}$ \\ ${ }^{1}$ Department of Critical Medicine, Ordos Central Hospital, Ordos; ${ }^{2}$ Department of Respiratory and Critical Medicine, \\ The Third Affiliated Hospital of Inner Mongolia Medical University, Baotou, \\ Inner Mongolia Autonomous Region 014010, P.R. China
}

Received October 24, 2014; Accepted October 6, 2015

DOI: $10.3892 /$ etm.2015.2884

\begin{abstract}
The present study aimed to investigate whether genetic polymorphisms in the Toll-like receptor (TLR)-4 and Toll/interleukin-1 receptor (TIR)-associated protein (TIRAP) genes, and/or their expression levels, influence the susceptibility of a patient to sepsis. A total of 106 patients with sepsis were divided into two groups on the basis of their acute physiology and chronic health evaluation (APACHE) II scores: i) Sepsis group A (APACHE II <20) and ii) Sepsis group B (APACHE II $>20$ ). In addition, 100 healthy volunteers were enrolled into the control group. Polymerase chain reaction-restriction fragment length polymorphism assay was used to detect the following genetic polymorphisms: The Ser180Leu allele of the TIRAP gene and the Asp299Gly and Thr399I1e alleles of the TLR4 gene. Furthermore, the protein expression levels of TLR4 and TIRAP were analyzed using an enzyme-linked immunosorbent assay. Genetic polymorphisms were not detected for the TLR4 and TIRAP genes; however, the protein expression levels of TLR4 and TIRAP differed significantly between the control, sepsis A and sepsis B groups $(\mathrm{P}<0.01)$. An APACHE II score of 20 was used as a baseline in order to differentiate sepsis severity. Pearson analysis demonstrated that TLR4 and TIRAP protein expression levels were positively correlated with sepsis severity $(r=0.931$ and 0.972 ; $\mathrm{P}<0.05)$, and TLR4 protein expression levels were positively correlated with those of TIRAP $(r=0.936 ; \mathrm{P}<0.05)$. The results of the present study suggested that the protein expression levels of, but not genetic polymorphisms in, TLR4 and TIRAP were associated with the severity of sepsis.
\end{abstract}

Correspondence to: Professor Jingping Yang, Department of Respiratory and Critical Medicine, The Third Affiliated Hospital of Inner Mongolia Medical University, 20 Shaoxian Road, Baotou, Inner Mongolia Autonomous Region 014010, P.R. China

E-mail: jingpingyang@126.com

Key words: sepsis, genetic polymorphisms, Toll-like receptor 4, Toll/interleukin-1 receptor-associated protein

\section{Introduction}

Systemic inflammatory response syndrome (SIRS), which occurs following systemic infection (sepsis), burns, shock and major surgery, is a type of cytokine storm, in which there is an abnormal upregulation of various cytokines (1). SIRS may lead to septic shock, multiple organ dysfunction syndrome (MODS) and an increased risk of mortality $(1,2)$. A prospective multicenter analysis of intensive care units (ICU) was previously conducted to assess the epidemiology of sepsis, which demonstrated that the incidence and mortality rates of sepsis were high, and that the annual cost of hospital care for patients with sepsis was expensive $(3,4)$. The incidence of sepsis has been shown to be affected by numerous factors, which involve disruption of inflammatory and immune responses $(1,2,5)$.

The Toll-like receptor (TLR) family has an important role in the immune response, and recognizes pathogen-associated molecular patterns (PAMPs) in order to activate inflammatory signaling pathways $(6,7)$. Lipopolysaccharide (LPS), which is released by gram-negative bacteria and is a type of PAMP, is recognized by TLR4, which subsequently initiates a signaling cascade that leads to the upregulation of specific cytokines that have previously been associated with the occurrence and development of sepsis (7-9). Previous studies reported that the risk of sepsis, and its mortality rate, was higher in European populations, as compared with other regional populations $(7,8)$. Single nucleotide polymorphisms (SNPs) have been shown to affect the development of immune and inflammatory reactions (7-10), and there is an issue regarding the significance and distribution of TLR4 genetic polymorphisms among various ethnicities $(7,8,10)$.

In order to investigate whether TLR4 and Toll/interleukin-1 receptor (TIR)-associated protein (TIRAP) genetic polymorphisms, and/or their expression levels, influence the susceptibility of an individual to sepsis, the present study analyzed the sequences and expression levels of TLR4 and TIRAP in 106 patients from the ICU of our hospital. In particular, the following genetic polymorphisms were analyzed: The Ser180Leu allele of the TIRAP gene, and the Asp299Gly and Thr399I1e alleles of the TLR4 gene. 


\section{Materials and methods}

Subjects. A total of 106 patients with sepsis were enrolled in the present study. The patients were admitted to the medical ICU between October 2012 and May 2013. At the time of enrollment, the acute physiology and chronic health evaluation (APACHE II) scores were recorded for each patient (11). On the basis of the APACHE II scores, all patients were divided into either sepsis group A (APACHE II score <20; male, 43; female, 37) or sepsis group B (APACHE II score $>20$; male, 14 ; female, 12 ). The ratio of male to female participants was 1.5 to 1 , and the mean age was 60 -years-old (range, 44-80 years). All patients satisfied the diagnostic criteria of the International Sepsis Conference of Washington, December 2001 (12). In addition, 100 healthy individuals, including 58 males and 42 females (age range, 40-75 years), from the Medical Examination Center in our hospital were enrolled in a control group. All individuals in the control group were without disease or a history of recent infection. There were no significant differences in age and gender between the sepsis groups and the control group. The present study was conducted in accordance with the Declaration of Helsinki, and with approval from the Ethics Committee of Inner Mongolia Medical University (Baotou, China). Written informed consent was obtained from all participants.

Collection of specimens. Venous blood samples $(4 \mathrm{ml})$ were collected from all patients, and $2 \mathrm{ml}$ blood was added to anticoagulant tubes containing $2 \%$ ethylenediaminetetraacetic acid, which were subsequently stored at $-80^{\circ} \mathrm{C}$. Another $2 \mathrm{ml}$ blood was centrifuged at $685 \mathrm{x}$ g for $5-7 \mathrm{~min}$, and the separated serum was stored in tubes at $-80^{\circ} \mathrm{C}$. The storage method used was the gradient temperature-reduction method (13).

Extraction of genomic DNA and polymerase chain reaction $(P C R)$. Genomic DNA samples were extracted from peripheral blood samples using the Blood Gen Mini kit (Beijing ComWin Biotech, Co., Ltd., Beijing, China), according to the manufacturer's protocol. The TIRAP (Ser180Leu) and TLR4 (Asp199Gly, Thr399I1e) genes were amplified using the Veriti ${ }^{\mathrm{TM}} 96$ PCR Amplifier (Applied Biosystems; Thermo Fisher Scientific, Inc., Waltham, MA, USA), in which the primers used were as follows: TLR4 (Asp299Gly) forward, 5'-ATACTTAGACTACTACCTCCATG-3' and reverse, 5'-TTGTTGGAAGTGAAAGTAAG-3'; TLR4 (Thr399I1e) forward, 5'-TGTTATCAAAGTGATTTTGGGAGAA-3' and reverse, 5'-AGGTAAATGAGGTTTCTGAGTGATAGG-3'; and TIRAP/MyD88-adaptor-like (Mal) (Ser180Leu): forward, 5'-AGTGCTGTACCATCGACCTGCTG-3' and reverse 5'-TTCCCСТTCTCCCTCCTGTAGTAG-3'. All primers were synthesized by Sangon Biotech Co. Ltd. (Shanghai, China). Each amplification reaction was conducted in a total volume of $50 \mu \mathrm{l}$ reaction mixture, including $16 \mu \mathrm{l}$ genomic DNA, $2 \mu \mathrm{l}$ forward primer and $2 \mu \mathrm{l}$ reverse primer, $25 \mu \mathrm{l} \mathrm{Taq}$ 2X PCR Master Mix (Beijing Tiangen Biotech, Co., Ltd., Beijing, China) and $5 \mu 1$ nuclease-free water. Following initial denaturation at $94^{\circ} \mathrm{C}$ for $3 \mathrm{~min}$, the genomic DNA was amplified by 35 cycles of PCR $\left(94^{\circ} \mathrm{C}\right.$ for $30 \mathrm{sec}, 58^{\circ} \mathrm{C}$ for $45 \mathrm{sec}$, and $72^{\circ} \mathrm{C}$ for $1 \mathrm{~min}$ ), which was followed by a final $5 \mathrm{~min}$ extension at $72^{\circ} \mathrm{C}$.
The PCR products $(30 \mu \mathrm{l})$ were separated by $2 \%$ agarose gel electrophoresis, and were visualized by staining with $0.5 \mu \mathrm{g} / \mathrm{ml}$ ethidium bromide (Thermo Fisher Scientific, Inc.) in an Electrophoresis Meter $(100 \mathrm{~V} ; 50 \mathrm{~A} ; 30 \mathrm{~min}$; Wide Mini-Sub ${ }^{\circledR}$ Cell GT; Bio-Rad Laboratories, Inc., Hercules, CA, USA). Images were then captured under ultraviolet (UV) light. DNA Marker I (Beijing ComWin Biotech, Co., Ltd.) was used as a standard. Subsequently, the PCR products were purified using the Midi Purification kit (Beijing Tiangen Biotech, Co., Ltd.).

Restriction fragment length polymorphism (RFLP). Purified Asp299Gly (TLR4), Thr399I1e (TLR4) and Ser180Leu (TIRAP) alleles were digested using the restriction enzymes NcoI, HinfI and Eam1105I, respectively (Thermo Fisher Scientific, Inc.). The enzyme digestion reaction mixture consisted of $2 \mu \mathrm{l} 10 \mathrm{X}$ FastDigest Green Buffer (Thermo Fisher Scientific, Inc.), $2 \mu 1$ restriction enzyme (NcoI, HinfI or Eam1105I), $10 \mu \mathrm{l}$ PCR products and $6 \mu \mathrm{l}$ nuclease-free water. The reaction occurred at $37^{\circ} \mathrm{C}$ for $5 \mathrm{~min}$, after which the genotypes were separated by $2 \%$ agarose gel electrophoresis (labclinics, Barcelona, Spain), and visualized using ethidium bromide staining, UV illumination and image capturing. DNA Marker 20 (Takara Bio, Inc., Otsu, Japan) was used as an internal standard.

PCR products $(20 \mu \mathrm{l})$ prior to enzyme digestion and $10 \mu 1$ each of the forward and reverse primers for TLR4 (Asp299Gly, Thr399I1e) and TIRAP (Ser180Leu) were sequenced by the Beijing Genomics Institute (BGI; Beijing, China). Sequencing results were investigated using Chromas 2.31 software (Technelysium, Pty Ltd., South Brisbane, Australia). TA repeat sequences upstream of the A(TA)nTAA polymorphism in the promoter region of the UDP glucuronosyltransferase 1 family gene were analyzed using CLC Sequence Viewer software (version 4.6.1; CLC bio, Waltham, MA, USA) to conduct sequence alignments with template sequences in the GenBank database (Human TLR4, NC_000009; Human TIRAP, NC_000011; http://www.ncbi. nlm.nih.gov/genbank/).

Enzyme-linked immunosorbent assay (ELISA). The protein expression levels of TLR4 and TIRAP in peripheral blood samples were detected using the Human TLR4 and TIRAP ELISA kits (R\&D Systems, Inc., Minneapolis, MN, USA), in accordance with the manufacturer's protocol (Thermo Scientific Multiskan MK3; Thermo Fisher Scientific, Inc.).

Statistical analysis. Statistical analyses were conducted using the statistical SPSS17.0 software package (SPSS, Inc., Chicago, IL, USA). Quantitative variables were expressed as the mean \pm standard deviation. Comparisons of continuous variables between two groups were conducted using one-way analysis of variance (ANOVA) for parameters with a normal distribution, and the rank-sum test for parameters with an abnormal distribution. Three-way ANOVA was used in order to compare differences among the three groups. In addition, the genetic frequencies test was used to assess the Hardy-Weinberg equilibrium. Differences in genotype distributions among the groups were analyzed using the $\chi^{2}$ test. $\mathrm{P}<0.05$ was considered to indicate a statistically significant difference. 
A

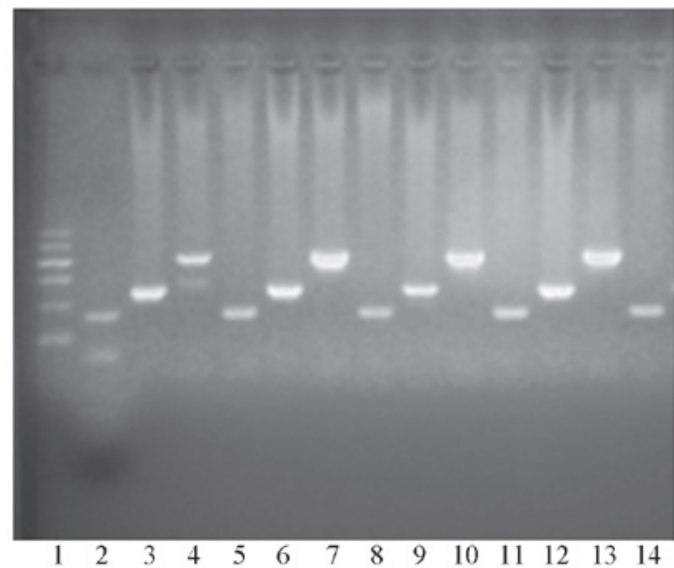

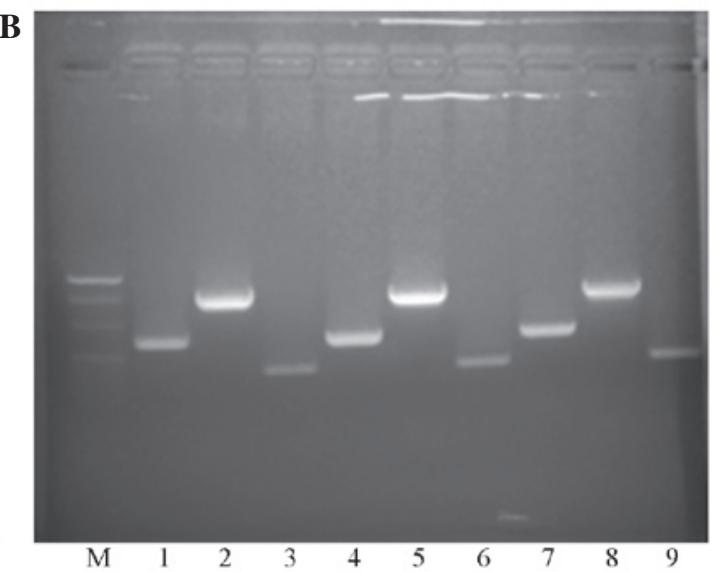

$\begin{array}{lllllllllll}M & 1 & 2 & 3 & 4 & 5 & 6 & 7 & 8 & 9\end{array}$

Figure 1. (A) Electrophoresis of polymerase chain reaction (PCR) products. Lane 1, DNA Marker I (100, 200, 300, 400, 500 and 600 bp, from top-to-bottom); lane 2, positive control; lanes 3, 6, 9 and 12, Asp299Gly (TLR4) gene (218 bp); lanes 4, 7, 10 and 13, Thr399Ile (TLR4) gene (405 bp); lanes 5, 8, 11 and 14, Ser180Leu (TIRAP/Mal) gene (161 bp). (B) Electrophoresis of purified PCR products. Lane M, DNA Marker 20 (200,300, 400 and 500 bp, from top-to-bottom); lanes 1, 4 and 7, Asp299Gly (TLR4) gene (218 bp); lanes 2, 5 and 8 Thr399Ile (TLR4) gene (405 bp); lanes 3, 6 and 9 Ser180Leu (TIRAP/Mal) gene (161 bp).

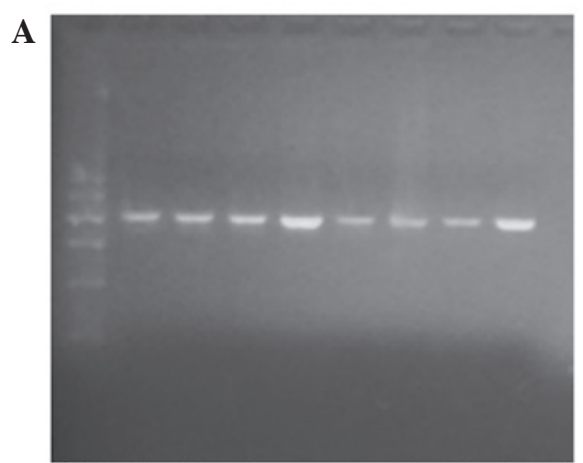

$\begin{array}{lllllllll}M & 1 & 2 & 3 & 4 & 5 & 6 & 7 & 8\end{array}$
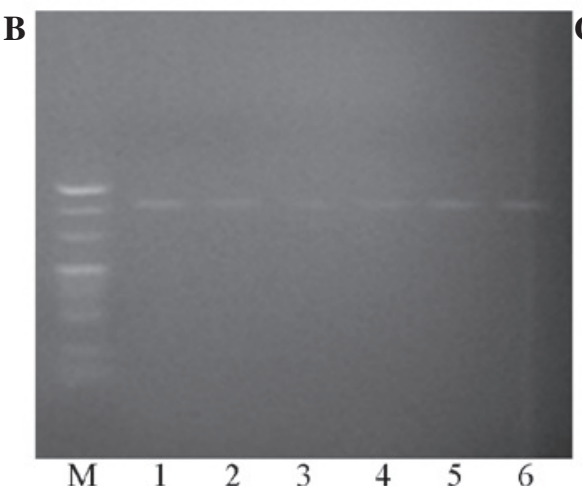

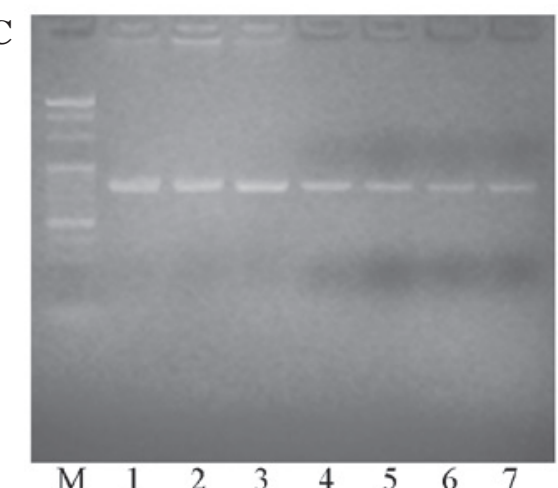

$\begin{array}{llllllll}\mathrm{M} & 1 & 2 & 3 & 4 & 5 & 6 & 7\end{array}$

Figure 2. Electrophoresis of polymerase chain reaction products following digestion with restriction enzymes. (A) Toll-like receptor (TLR)4 Asp299Gly allele digested with the NcoI restriction enzyme; (B) TLR4 Thr399Ile allele digested with the HindI restriction enzyme; and (C) Toll/interleukin-1 receptor-associated protein Ser180Leu allele digested with the Eam1105I restriction enzyme. Lane M, DNA Marker I (20, 80, 100, 200, 400 and 600 bp, from top-to-bottom). Lanes 1-8 correspond to the numbers of the samples.

\section{Results}

PCR products. The PCR products were separated by agarose gel electrophoresis, and were visualized by staining with ethidium bromide under UV light. (Fig. 1). Each band on the electrophoretogram represents a single PCR product, including TLR4 (Asp299Gly; 218 bp), TLR4 (Thr399I1e; 405 bp) and TIRAP (Ser180Leu; $161 \mathrm{bp).}$

Confirmation of enzyme digestion. Purified PCR products were digested using restriction enzymes and were separated by agarose gel electrophoresis (Fig. 2). A single band corresponding to the TLR4 Asp299Gly allele occurred at $218 \mathrm{bp}$ following digestion by the NcoI restriction enzyme; thus indicating the presence of the Asp/Asp genotype only (Fig. 2A). In addition, a single band corresponding to the TLR4 Thr399I1e allele occurred at 405 bp following digestion by the HindI restriction enzyme; thus indicating the presence of the Thr/Thr genotype only (Fig. 2B). Furthermore, a single band corresponding to the TIRAP Ser180Leu allele occurred at $161 \mathrm{bp}$ following digestion by the Eam1105I restriction enzyme, which suggested that only the Ser/Ser genotype was present (Fig. 2C). These results indicated that the purified TLR4 and TIRAP genes were not digested by the restriction enzymes; thus suggesting that there were no genetic polymorphisms in the TLR4 and TIRAP genes in the sepsis groups, as compared with the control group.

Gene sequencing. Following enzyme digestion, all PCR products were sequenced by the BGI, which confirmed the gene sequences and mutations (Fig. 3). Sequencing results demonstrated that the three gene maps were almost identical to the template sequences in Genbank. Using the Chromas 2.31 software, sequence alignments of ten samples demonstrated that there were no mutations in the TLR4 (Asp299Gly, Thr399I1e) and TIRAP (Ser180Leu) genes in the sepsis group, as compared with the control group (Figs. 4, 5 and 6).

TLR4 and TIRAP protein expression levels. TLR4 and TIRAP protein expression levels were significantly different between 
A

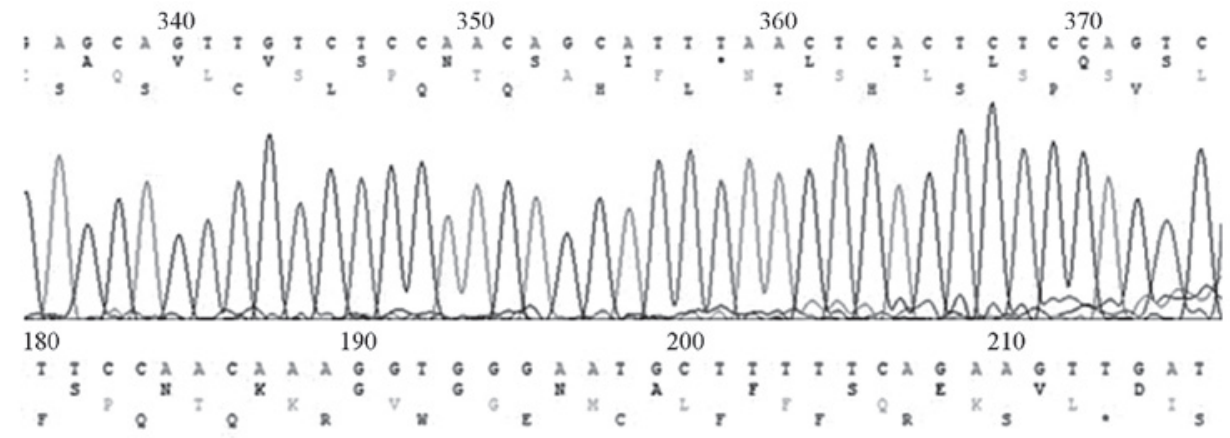

$\mathbf{B}$

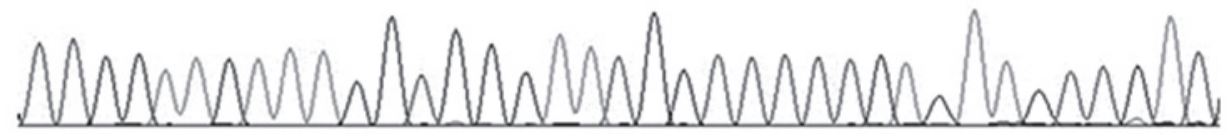

C

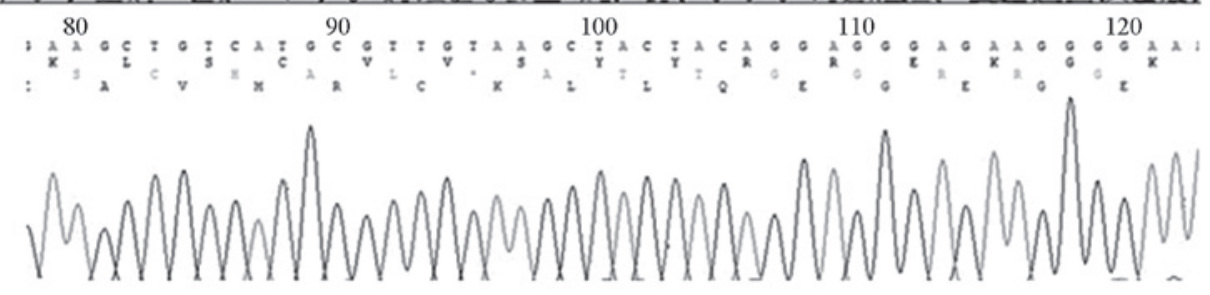

Figure 3. Representative sequence diagram of the Toll-like receptor 4 (A) Asp299Gly and (B) Thr399Ile alleles, and the (C) Toll/interleukin-1 receptor-associated protein Ser180Leu gene.

Table I. Protein expression levels of TLR4 and TIRAP (ng/ml; $\mathrm{n}=206)$.

\begin{tabular}{|c|c|c|c|c|c|}
\hline & Control group & $\begin{array}{c}\text { Sepsis group A } \\
\text { (APACHE } \mathrm{II} \leq 20)\end{array}$ & $\begin{array}{c}\text { Sepsis group B } \\
\text { (APACHE II>20) }\end{array}$ & F value & P-value \\
\hline TLR4 & $0.886 \pm 0.058^{\mathrm{a}, \mathrm{b}}$ & $2.253 \pm 0.379^{c}$ & $4.494 \pm 0.709$ & 116.550 & $<0.001$ \\
\hline TIRAP & $5.216 \pm 0.410^{\mathrm{a}, \mathrm{b}}$ & $9.540 \pm 2.294^{c}$ & $19.206 \pm 1.755$ & 94.950 & $<0.001$ \\
\hline
\end{tabular}

the control, sepsis A and sepsis B groups (TLR4: $\mathrm{F}=116.550$, $\mathrm{P}<0.01$; TIRAP: $\mathrm{F}=94.950, \mathrm{P}<0.01$; Table I).

An APACHE II score of 20 was used as a baseline in order to differentiate sepsis severity. Pearson analysis demonstrated that TLR4 and TIRAP protein expression levels were positively correlated with sepsis severity (TLR4: $r=0.931, \mathrm{P}<0.05$; TIRAP: $r=0.972, \mathrm{P}<0.05$; Table I). Furthermore, the TLR4 protein expression levels were positively correlated with the TIRAP protein expression levels $(r=0.936$; $\mathrm{P}<0.05$; Table I).

\section{Discussion}

SNPs are the most common type of human genetic variant, accounting for $2-3 \mathrm{~cm}$ of the human genome, and occurring at a higher density than microsatellites (14). In addition, SNPs that exhibit a high genetic stability may directly affect protein expression or structure and therefore underlie numerous genetic disorders ( $30 \%$ SNPs have been associated with disease) (15). Furthermore, SNPs have previously been associated with the metabolism of numerous drugs. Therefore, the analysis of SNPs has been widespread in biomedical research and drug development (15).

In previous studies, specific genetic polymorphisms have been associated with the susceptibility to, and clinical features and prognosis of, sepsis $(9,16)$. In addition, it has been suggested that genetic variation may influence sepsis development and increase the risk of MODS during severe infections (16). Furthermore, TLR-mediated signaling pathways have a critical role in the mechanisms underlying the development of sepsis, and alterations in TLR gene structures have previously been associated with susceptibility to sepsis and sepsis severity (17).

The majority of sepsis cases $(>50 \%)$ are caused by gram-negative bacteria, which are predominantly recognized by TLR4 (18). Previous studies reported that C3H/HeJ TLR4 gene knock-out mice exhibited low sensitivity to LPS $(19,20)$. In addition, Hagberg et al (21) reported that $\mathrm{C} 3 \mathrm{H} / \mathrm{HeJ}$ mice exhibited significantly increased susceptibility to gram-negative bacteria in an experimental model of urinary tract infections. However, TLR4 variation was not associated with the development of organ injury or cellular stress responses in 


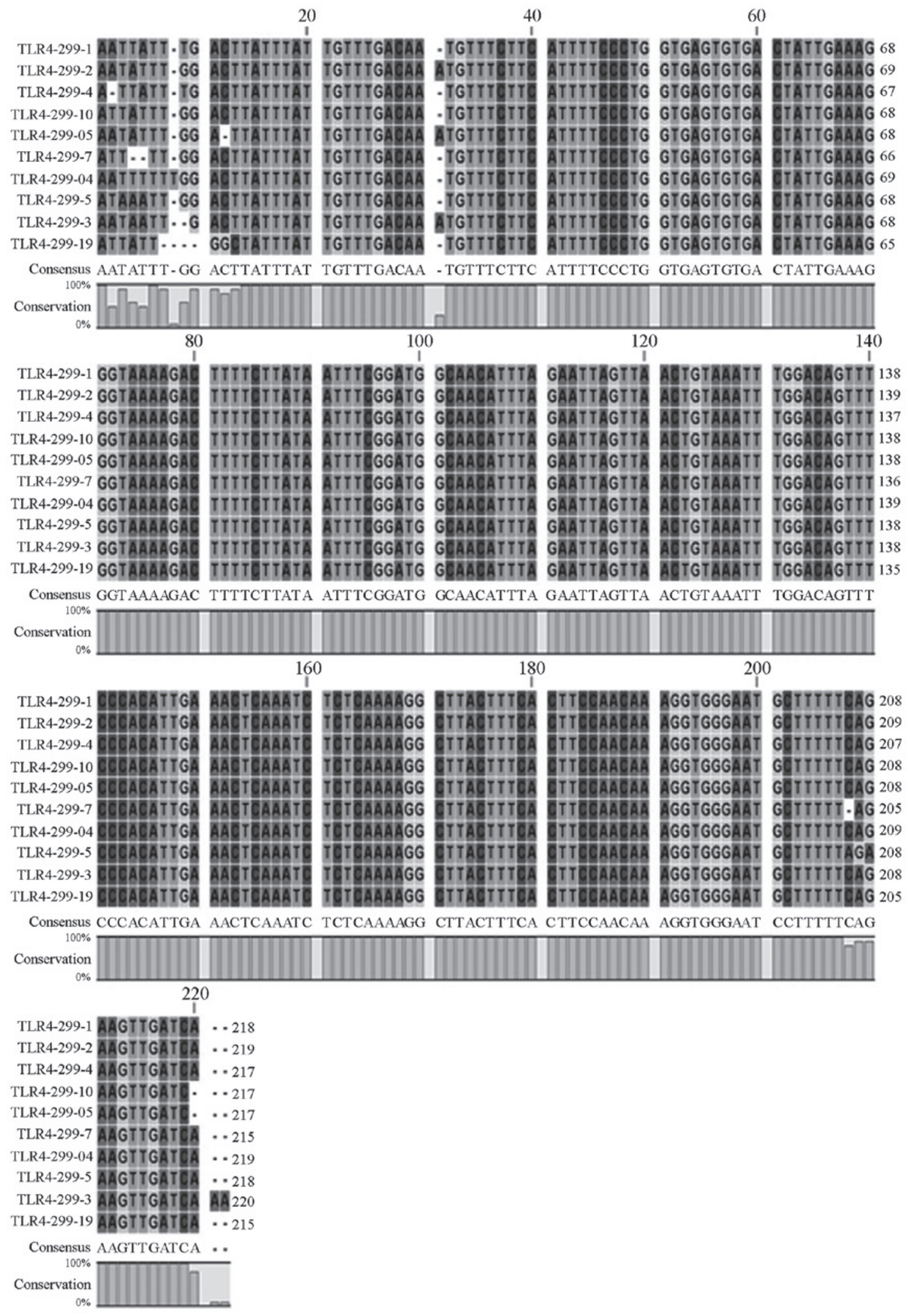

Figure 4. Sequencing results of the Toll-like receptor (TLR)4 (Asp299Gly) gene using Chromas 2.31 software. TLR4-04 and -05 correspond to sequences from the control group, whereas all others correspond to sequences from the sepsis groups.

severe sepsis. Therefore, there exists a controversy regarding the effects of TLR4 genetic polymorphisms on the susceptibility to and development of sepsis.

Various mutations in the extracellular domain of TLR4 have been identified, including Asp299Gly and Thr399I1e substitution mutations (22). Arbour et al (23) demonstrated that the Asp299Gly mutation was able to interrupt TLR4-mediated LPS signaling, whereas Schröder and Schumann (24) were unable to identify a direct correlation between Asp299Gly genetic polymorphisms and susceptibility to infections 


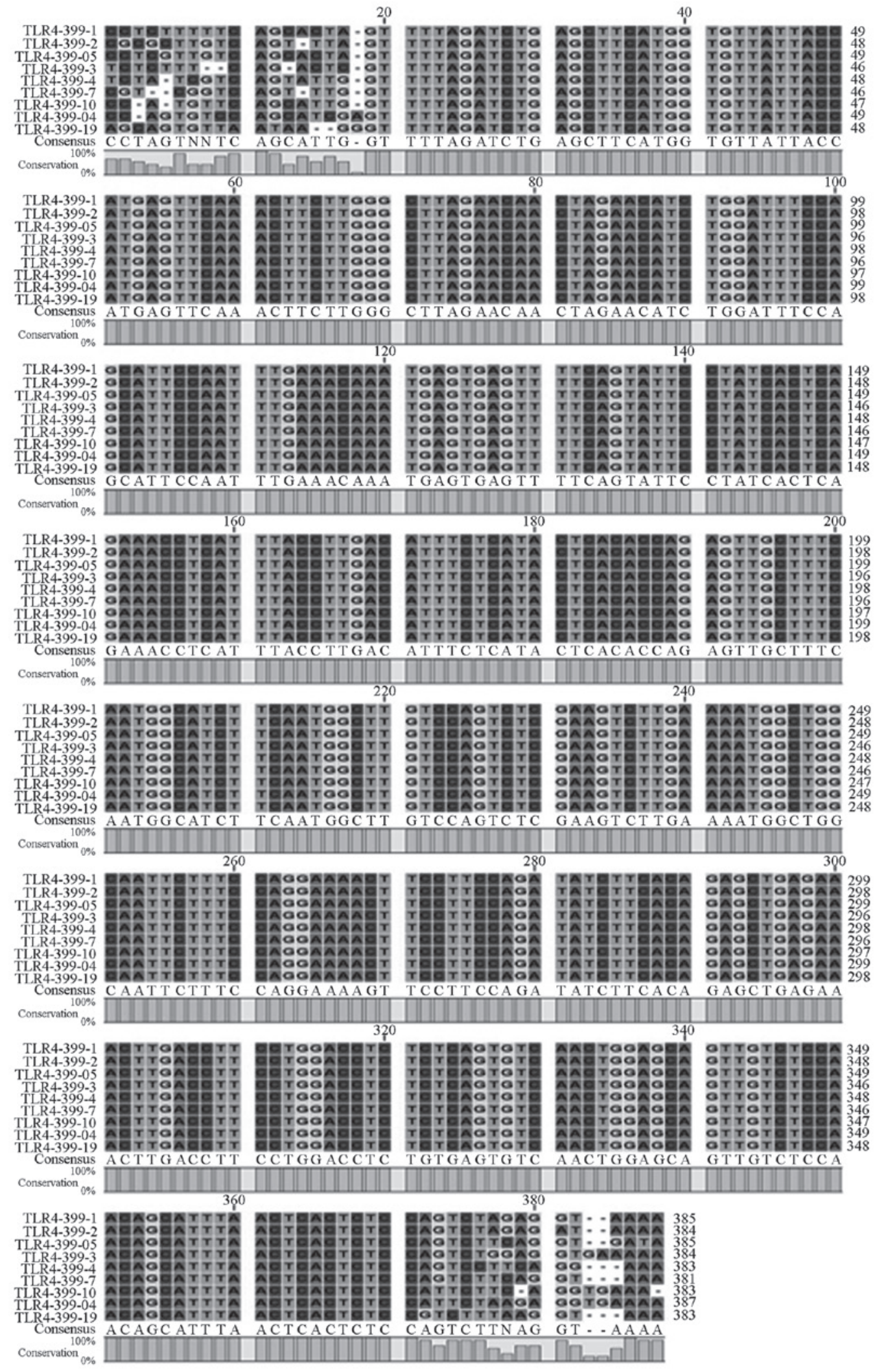

Figure 5. Sequencing results of the Toll-like receptor (TLR)4 (Thr399I1e) gene using Chromas 2.31 software. TLR4-04 and -05 correspond to sequences from the control group, whereas all others correspond to sequences from the sepsis groups.

caused by gram-negative bacteria. It is possible that the Asp299Gly and Thr399I1e alleles exhibit co-segregation, including the wild-type/wild-type, Asp299Gly/wide-type, Thr399I1e/wide-type and Asp299Gly/Thr399Ile haplotypes. A previous study demonstrated that the Asp299Gly/wild-type haplotype was associated with increased LPS-induced release of tumor necrosis factor (TNF)- $\alpha$ (25); however, there was no significant difference between the other haplotypes and the release of TNF- $\alpha$. In addition, as the Asp299Gly/wild-type polymorphism is uncommon in the human population, there 


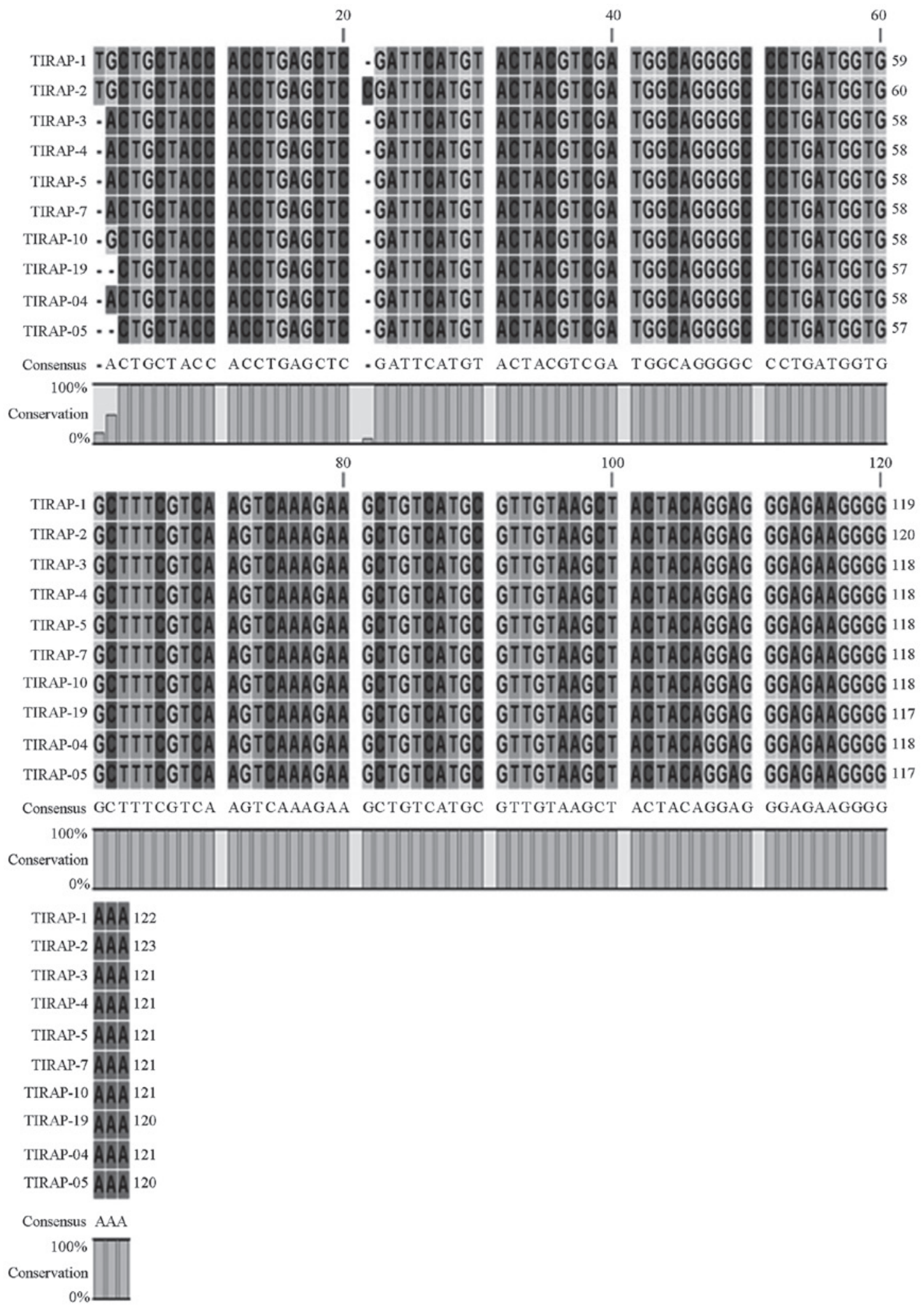

Figure 6. Sequencing results of the Toll/interleukin-1 receptor-associated protein (TIRAP) Ser180Leu allele using Chromas 2.31 software. TIRAP-04 and -05 correspond to the control group, whereas all others correspond to sequences from the sepsis groups.

is no confidence that the association between this haplotype and susceptibility to gram-negative bacteria is relevant to humans (25).

The incidence and development of sepsis may be associated with polygenic polymorphisms. The present study enrolled 106 patients previously diagnosed with sepsis, and sequenced the Asp299Gly and Thr399Ile alleles of TLR4; however, mutations in these alleles were not identified. These results are consistent with a previous study which reported that the Asp299Gly allele was associated with sepsis in the European population, but not in the Asian population, and that the Asp299Gly and Thr399I1e TLR4 
genetic polymorphisms are uncommon in the Asian population (25). In addition, Okayama et al (26) were unable to detect the Asp299Gly allele of the TLR4 gene in specimens from Japanese patients, and Lin et al (27) analyzed DNA samples from healthy individuals and patients with shock in the Chinese Han population, and were unable to identify Asp299Gly polymorphisms.

TLR-mediated signaling involves at least four intracellular signaling adaptor molecules, including TIRAP, which is also known as Mal (28). TIRAP/Mal acts as a bridging adaptor, which has an important role in downstream inflammatory responses mediated by TLR 2 and TLR4 (29). In addition, genetic polymorphisms in TIRAP/Mal have been shown to affect the incidence and development of diseases (30). Kumpf et al (30) suggested that the TIRAP Ser180Leu (rs8177374) allele may increase susceptibility to infections. Furthermore, previous studies reported that TIRAP (rs8177374 and rs7932766) polymorphisms may influence the production of inflammatory cytokines and have important consequences for the susceptibility to and severity of infections (31). However, the present study was unable to identify the rs8177374 polymorphism, which was consistent with previous studies that demonstrated that the frequencies of the rs8177374 and rs7932766 alleles were higher in European populations, as compared with Asian populations, and were in fact rarely detected in Asian populations $(31,32)$.

TLR4 and TIRAP have important roles in TLR-mediated inflammatory signaling pathways in severe immune responses (33). In addition, alterations in the expression levels of TLR4 and TIRAP have previously been associated with the extent of inflammatory reactions (33). Tsujimoto et al (34) reported that the serum TLR4 protein expression levels increased following infection of patients with pathogens, and that the protein expression levels of TLR4 increased markedly in patients with sepsis. Numerous studies have previously demonstrated that the severity of acute lung injury was dependent on systemic inflammatory reactions $(35,36)$. As TIRAP activates intracellular signaling pathways via TLR-mediated recognition of various types of pathogen, the TIRAP adaptor protein has an integral role in the development of acute lung injury. TIRAP is essential for MyD88-dependent signaling downstream of TLR2 and TLR4 (its expression was shown to increase following stimulation of TLR2 and TLR4), initiating a signaling cascade that culminates in the nuclear localization of nuclear factor- $\mathrm{\kappa B}$ and the activation of the pro-inflammatory response (37).

In the present study, the protein expression levels of TLR4 and TIRAP were significantly different among the control group, sepsis group A (APACHE II<20) and sepsis group B (APACHE II $\geq 20$ ). An APACHE II score of 20 was used as a baseline in order to differentiate sepsis severity, and Pearson analysis demonstrated that the protein expression levels of TLR4 and TIRAP were positively correlated with sepsis severity. In addition, the TLR4 protein expression levels were positively correlated with the TIRAP protein expression levels. These results suggested that the inflammatory response and severity of sepsis were associated with serum TLR4 and TIRAP protein expression levels.

The present study was unable to detect specific polymorphisms in the TIRAP (Ser180Leu) and TLR4 genes
(Asp299Gly, Thr399I1e), which may have been associated with susceptibility to sepsis and sepsis severity. However, the protein expression levels of TLR4 and TIRAP in peripheral blood samples were positively correlated with sepsis severity, and were shown to have synergistic effects. It is possible that other previously described polymorphisms in the TLR4 and TIRAP genes may be associated with susceptibility to sepsis, and these should be the focus of future studies.

\section{References}

1. Fry DE: Sepsis, systemic inflammatory response and multiple organ dysfunction: The mystery continues. Am Surg 78: 1-8, 2012.

2. Maloney PJ: Sepsis and septic shock. Emerg Med Clin North Am 31: 583-600, 2013.

3. Lopez-Bushnell K, Demaray WS and Jaco C: Reducing sepsis mortality. Med Surg Nurs 23: 9-14, 2014.

4. Mayr FB, Yende S and Angus DC: Epidemiology of severe sepsis. Virulence 5: 4-11, 2014.

5. Martin GS: Sepsis, severe sepsis and septic shock: Changes in incidence, pathogens and outcomes. Expert Rev Anti Infect Ther 10: 701-706, 2012.

6. Wiersinga WJ, Leopold SJ, Cranendonk DR and van der Poll T: Host innate immune responses to sepsis. Virulence 5: 36-44, 2014.

7. Esposito S, Molteni CG, Zampiero A, Baggi E, Lavizzari A, Semino M, Daleno C, Groppo M, Scala A, Terranova L, et al: Role of polymorphisms of toll-like receptor (TLR) 4, TLR9, toll-interleukin 1 receptor domain containing adaptor protein (TIRAP) and FCGR2A genes in malaria susceptibility and severity in Burundian children. Malar J 11: 196, 2012.

8. Plantinga TS, Ioana $\mathrm{M}$, Alonso $\mathrm{S}$, Izagirre $\mathrm{N}$, Hervella $\mathrm{M}$, Joosten LA, van der Meer JW, de la Rúa C and Netea MG: The evolutionary history of TLR4 polymorphisms in Europe. J Innate Immun 4: 168-175, 2012.

9. Namath A and Patterson AJ: Genetic polymorphisms in sepsis. Crit Care Clin 25: 835-856, 2009.

10. Yang H, Wei C, Li Q, Shou T, Yang Y, Xiao C, Yu M, Li M, Yang $\mathrm{Z}$, Zhang $\mathrm{J}$ and Zheng B: Association of TLR4 gene non-missense single nucleotide polymorphisms with rheumatoid arthritis in Chinese Han population. Rheumatol Int 33: 1283-1288, 2013.

11. Sekulic AD, Trpkovic SV, PavlovicAP, Marinkovic OM and Ilic AN: Scoring systems in assessing survival of critically ill ICU patients. Med Sci Monit 21:2621-2629, 2015.

12. Levy MM, Fink MP, Marshall JC, Abraham E, Angus D, Cook D, Cohen J, Opal SM, Vincent JL and Ramsay G; SCCM/ESICM/ACCP/ATS/SIS: 2001 SCCM/ESICM/ACCP/ATS/SIS International Sepsis Definitions Conference. Crit Care Med 31: 1250-1256, 2003.

13. Sunna A, Gibbs MD, Chin CW, Nelson PJ and Bergquist PL: A gene encoding a novel multidomain beta-1,4-mannanase from Caldibacillus cellulovorans and action of the recombinant enzyme on kraft pulp. Appl Environ Microbiol 66: 664-670, 2000.

14. Jin SB, Zhang XF, Lu JG, Fu HT, Jia ZY and Sun XW: Genetic analysis of QTL for eye cross and eye diameter in common carp (Cyprinus carpio L.) using microsatellites and SNPs. Genet Mol Res 14: 3557-3569, 2015.

15. Chen HY, Huang W, Leung VH, Fung SL, Ma SL, Jiang H and Tang NL: Functional interaction between SNPs and microsatellite in the transcriptional regulation of insulin-like growth factor 1. Hum Mutat 34: 1289-1297, 2013.

16. Papathanassoqlou ED, Giannakopoulou MD and Bozas E: Genomic variations and susceptibility to sepsis. AACN Adv Crit Care 17: 394-422, 2006.

17. Salomao R, Brunialti MK, Gomes NE, Mendes ME, Diaz RS, Komninakis S, Machado FR, da Silva ID and Rigato O: Toll-like receptor pathway signaling is differently regulated in neutrophils and peripheral mononuclear cells of patients with sepsis, severe sepsis, and septic shock. Crit Care Med 37:132-139, 2009.

18. Angus DC, Linde-Zwirble WT, Lidicker J, Clermont G, Carcillo J and Pinsky MR: Epidemiology of severe sepsis in the United States: Analysis of incidence, outcome and associated costs of care. Crit Care Med 29: 1303-1310, 2001. 
19. Akira S, Takeda K and Kaisho T: Toll-like receptors: Critical proteins linking innate and acquired immunity. Nat Immunol 2: 675-680, 2001

20. Janeway CA Jr and Medzhitov R: Innate immune recognition. Annu Rev Immunol 20: 197-216, 2002.

21. Hagberg L, Hull R, Hull S, McGhee JR, Michalek SM and Svanborg Edén C: Difference in susceptibility to gram-negative urinary tract infection between $\mathrm{C} 3 \mathrm{H} / \mathrm{HeJ}$ and $\mathrm{C} 3 \mathrm{H} / \mathrm{HeN}$ mice. Infect Immun 46: 839-844, 1984.

22. Song Z, Yin J, Yao C, Sun Z, Shao M, Zhang Y, Tao Z, Huang P and Tong $C$ : Variants in the Toll-interacting protein gene are associated with susceptibility to sepsis in the Chinese Han population. Crit Care 15: R12, 2011.

23. Arbour NC, Lorenz E, Schutte BC, Zabner J, Kline JN, Jones M, Frees K, Watt JL and Schwartz DA: TLR4 mutations are associated with endotoxin hyporesponsiveness in humans. Nat Genet 25: 187-191, 2000.

24. Schröder NW and Schumann RR: Single nucleotide polymorphisms of Tol-1like receptors and susceptibility to infectious disease. Lancet Infect Dis 5: 156-164, 2005.

25. Ferwerda B, McCall MB, Alonso S, Giamarellos-Bourboulis EJ, Mouktaroudi M, Izagirre N, Syafruddin D, Kibiki G, Cristea T, Hijmans A, et al: TLR4 polymorphisms, infectious diseases, and evolutionary pressure during migration of modern humans. Proc Natl Acad Sci USA 104: 16645-16650, 2007.

26. Okayama N, Fujimura K, Suehiro Y, Hamanaka Y, Fujiwara M, Matsubara T, Maekawa T, Hazama S, Oka M, Nohara H, et al: Simple genotype analysis of the Asp299Gly polymorphism of the toll-like receptor- 4 gene that is associated with lipopolysaccharide hyporesponsiveness. J Clin Lab Anal 16: 56-58, 2002.

27. Lin YC, Chang YM, Yu JM, Yen JH, Chan JG and Hu CJ: Toll-like receptor 4 gene C119A but not Asp299Gly polymorphism is associated with ischemic stroke among ethnic Chinese in Taiwan. Atherosclerosis 180: 305-309, 2005 .

28. Hall C, Flores MV, Chien A, Davidson A, Crosier K and Crosier P: Transgenic zebrafish reporter lines reveal conserved Toll-like receptor signaling potential in embryonic myeloid leukocytes and adult immune cell lineages. J Leukoc Biol 85: $751-765,2009$
29. Couture LA, Piao W, Ru LW, Vogel SN and Toshchakov VY: Targeting Toll-like receptor (TLR) signaling by Toll/interleukin-1 receptor (TIR) domain-containing adapter protein/MyD88 adapter-like (TIRAP/Mal)-derived decoy peptides. J Biol Chem 287: 24641-24648, 2012.

30. Kumpf O, Giamarellos-Bourboulis EJ, Koch A, Hamann L, Mouktaroudi M, Oh DY, Latz E, Lorenz E, Schwartz DA, Ferwerda B, et al: Influence of genetic variations in TLR4 and TIRAP/Mal on the course of sepsis and pneumonia and cytokine release: An observational study in three cohorts. Crit Care 14: R103, 2010

31. Ferwerda B, Alonso S, Banahan K, McCall MB, Giamarellos-Bourboulis EJ, Ramakers BP, Mouktaroudi M, Fain PR, Izagirre N, Syafruddin D, et al: Functional and genetic evidence that the Mal/TIRAP allele variant $180 \mathrm{~L}$ has been selected by providing protection against septic shock. Proc Natl Acad Sci USA 106: 10272-10277, 2009.

32. Hamann L, Kumpf O, Schuring RP, Alpsoy E, Bedu-Addo G, Bienzle U, Oskam L, Mockenhaupt FP and Schumann RR: Low frequency of the TIRAP S180L polymorphism in Africa, and its potential role in malaria, sepsis, and leprosy. BMC Med Genet 10: 65, 2009.

33. Yew KH, Carpenter C, Duncan RS and Harrison CJ: Human cytomegalovirus induces TLR4 signaling components in monocytes altering TIRAP, TRAM and downstream interferon-beta and TNF-alpha expression. PLoS One 7: e44500, 2012.

34. Tsujimoto H, Ono S, Efron PA, Scumpia PO, Moldawer LL and Mochizki H: Role of toll-like receptors in the development of sepsis. Shock 29: 315-321, 2008.

35. Du L, Zhou J, Zhang J, Yan M, Gong L, Liu X, Chen M, Tao K, Luo $\mathrm{N}$ and Liu J: Actin filament reorganization is a key step in lung inflammation induced by systemic inflammatory response syndrome. Am J Respir Cell Mol Biol 47: 597-603, 2012.

36. Bhatia M, Zemans RL and JeyaseelanS: Role of chemokines in the pathogenesis of acute lung injury. Am J Respir Cell Mol Biol 46: 566-572, 2012.

37. Song Z, Tong C, Sun Z, Shen Y, Yao C, Jiang J, Yin J, Gao L, Song $\mathrm{Y}$ and Bai C: Genetic variants in the TIRAP gene are associated with increased risk of sepsis-associated acute lung injury. BMC Med Genet 11: 168, 2010. 